\title{
At home with hostility: How do pathogenic bacteria evade mammalian immune surveillance to establish persistent infection? Thomas Ruby and Denise M. Monack*
}

\author{
Address: Department of Microbiology and Immunology, Stanford University, 299 Campus Drive, Stanford, CA 94305, USA \\ *Corresponding author: Denise M. Monack (dmonack@stanford.edu) \\ FI000 Biology Reports 20II, 3:I (doi:I0.34I0/B3-I) \\ This is an open-access article distributed under the terms of the Creative Commons Attribution-Non Commercial License \\ (http://creativecommons.org/licenses/by-nc/3.0/legalcode), which permits unrestricted use, distribution, and reproduction in any medium, \\ provided the original work is properly cited. You may not use this work for commercial purposes. \\ The electronic version of this article is the complete one and can be found at: http://fl000.com/reports/b/3/I
}

\begin{abstract}
Bacterial persistence is of major concern as persistent bacterial infections involving bacteria such as Helicobacter pylori, Salmonella enterica serotype Typhi, and Mycobacterium tuberculosis pose significant public health problems worldwide. This report discusses the recent advances in understanding the strategies used by bacteria during persistent infection that allow them to colonize specific sites in the host and evade immune surveillance.
\end{abstract}

Long-term bacterial infections pose several fundamental biological questions: How metabolically active are bacteria during a persistent infection? Are they dividing, or in a state of quiescence? And how do these bacteria evade the immune system for so long?

Acute infections by pathogenic bacteria cause a dramatic activation of the innate and adaptive immune responses. If the pathogen survives initial contact with the host's innate immune system (and the host is not killed), the infection is usually cleared by the host's adaptive immune system. However, some bacterial pathogens maintain infections for the lifetime of their mammalian hosts, even in the presence of a robust immune response.

Most of what we've learned about persistent infections comes from the study of several well-known illnesses. For example, Helicobacter pylori, the cause of most stomach ulcers, inhabits the stomach lining, where its persistence can be lifelong; Mycobacterium tuberculosis is able to establish long-term infections that can manifest as acute or chronic versions of the lung disease, or be clinically asymptomatic yet retain the potential to reactivate; and Salmonella enterica, specifically the serotype Typhi, causes typhoid fever, a systemic infection that involves colonization of the reticuloendothelial system-the network of immune cells residing in some connective tissue. Some infected individuals become lifelong carriers, periodically shedding large numbers of bacteria in their stools. These persistently infected carriers serve as a reservoir for the pathogens, and are essential for survival of the bacteria within a restricted host population. In humans, infection with another serotype, Typhimurium, is normally associated with self-limiting gastroenteritis, and systemic disease is rare in most parts of the world.

However, a highly invasive form of nontyphoidal Salmonella (NTS) has become a major public health problem in parts of Africa. Although NTS strains do not normally persist in immunocompetent humans, there is serious concern about the potential that these strains might acquire that ability as they become more "humanadapted" [1].

We are only now beginning to understand the bacterial and host factors involved in the host-pathogen interaction during persistent infection, and these new discoveries are likely to provide new and exciting directions for research in the fields of microbial pathogenesis and immunology.

\section{Making a better replicative niche}

$H$. pylori is uniquely adapted to colonize the hostile environment of the human stomach. More virulent strains of $H$. pylori inject virulence factors into gastric epithelial 
cells, a step that is associated with the development of stomach cancer. These factors provide an advantage to the invading bacterium because they disrupt epithelial cell polarity. This allows bacteria to attach and grow on the apical surface of epithelial cells, where it may be easier for them to acquire the nutrients necessary for survival [2].

Salmonella has developed its own mechanisms for colonizing a host and replicating despite the presence of immune cells. Most of the information on Salmonella immuneevasion mechanisms has come from a mouse model of persistent Salmonella Typhimurium infection. Salmonella Typhimurium colonizes the mesenteric lymph nodes of these mice-a gathering place for immune cells-and is occasionally found in the gallbladder, liver, and spleen. One mechanism that Salmonella uses to subvert the immune system is to secrete the protein SseI into dendritic cells, which normally play a role in activating immunity. The bacterial protein interferes with the migration of infected cells to lymphoid tissues by specifically binding to the cell-migration regulator IQGAP. This prevents normal dendritic-cell migration, limiting presentation of Salmonella antigens and naive T-cell priming, and thereby inhibiting adaptive immunity $[3,4]$.

\section{Subverting the host}

Analyzing the role of host immune factors in chronic Salmonella infection has shed light on the mechanisms that allow for persistent bacterial growth. For example, regulatory $\mathrm{T}$ cells, which control the balance between immune-cell activation and suppression, can dictate the course of persistent Salmonella infection by suppressing the adaptive immune response. Leukocytes can also play a role in tuberculosis, where progression from a latent, subclinical infection to active disease is controlled by foamy macrophages within a granuloma (a spherical mass of immune cells that forms around a pathogen that can't be cleared). The foamy macrophage appears to be a key participant in both sustaining bacteria and contributing to the tissue pathology that leads to the release of infectious bacilli. The normally beneficial macrophages become pathologic in this situation through pathogen-initiated dysregulation of lipid synthesis [5].

Studying mechanisms of bacterial persistence is made more complex by the presence of native (nonpathogenic) organisms, particularly in the human gut. The human gut microflora is important in regulating host inflammatory responses and preventing inappropriate (anti-self) immune responses. Interactions between gut microbiota and the immune system are under intense study because of their potential effects on persistent infections and, therefore, on the health of an individual. Recent studies have delved further into our understanding of this relationship by identifying host-specific bacteria responsible for directly modulating the gut immune response towards Salmonella $[6,7]$. Further studies are now needed to evaluate the impact of the gut microbiota on the establishment of persistent systemic infections.

\section{Abbreviation}

NTS, nontyphoidal Salmonella.

\section{Competing interests}

The authors declare that they have no competing interests.

\section{Acknowledgments}

The authors would like to thank Manuel Amieva and Justin Sonnenburg for stimulating conversations.

\section{References}

I. Kingsley RA, Msefula CL, Thomson NR, Kariuki S, Holt KE, Gordon MA, Harris D, Clarke L, Whitehead S, Sangal V, Marsh K, Achtman M, Molyneux ME, Cormican M, Parkhill J, MacLennan CA, Heyderman RS, Dougan G: Epidemic multiple drug resistant Salmonella Typhimurium causing invasive disease in sub-Saharan Africa have a distinct genotype. Genome Res 2009, 19:2279-87.

FI000 Factor 6

Evaluated by Andreas Baumler 20 Apr 2010

2. Tan S, Tompkins LS, Amieva MR: Helicobacter pylori usurps cell polarity to turn the cell surface into a replicative niche. PLOS Pathog 2009, 5:el000407.

FI000 Factor 9

Evaluated by Jay Solnik OI Sep 2009

3. Lawley TD, Chan K, Thompson LJ, Kim CC, Govoni GR, Monack DM: Genome-wide screen for Salmonella genes required for longterm systemic infection of the mouse. PLoS Pathog 2006, 2:el I.

FI000 Factor 6

Evaluated by Francisco Garcia-del Portillo 14 Mar 2006

4. McLaughlin LM, Govoni GR, Gerke C, Gopinath S, Peng K, Laidlaw G, Chien YH, Jeong HW, Li Z, Brown MD, Sacks DB, Monack D: The Salmonella SPI2 effector Ssel mediates long-term systemic infection by modulating host cell migration. PLoS Pathog 2009, 5:el00067I.

FI000 Factor 6

Evaluated by Virginia Miller 06 Jan 2010

5. Russell DG, Cardona PJ, Kim MJ, Allain S, Altare F: Foamy macrophages and the progression of the human tuberculosis granuloma. Nat Immunol 2009, 10:943-8.

6. Gaboriau-Routhiau V, Rakotobe S, Lécuyer E, Mulder I, Lan A, Bridonneau C, Rochet V, Pisi A, De Paepe M, Brandi G, Eberl G, Snel J, Kelly $D$, Cerf-Bensussan $N$ : The key role of segmented filamentous bacteria in the coordinated maturation of gut helper T cell responses. Immunity 2009, 3 I:677-89.

FI000 Factor 6

Evaluated by Denise Monack 10 Dec 2009

7. Kelly D, Campbell Jl, King TP, Grant G, Jansson EA, Coutts AG, Pettersson S, Conway S: Commensal anaerobic gut bacteria attenuate inflammation by regulating nuclear-cytoplasmic shuttling of PPAR-gamma and RelA. Nat Immunol 2004, 5:104-12.

FI000 Factor 13

Evaluated by Casey Weaver II Mar 2004 